Check for updates

Cite this: Mater. Adv., 2022, 3, 918

Received 28th September 2021 Accepted 18th November 2021

DOI: 10.1039/d1ma00892g

rsc.li/materials-advances

\section{A critical review of hemoperfusion adsorbents: materials, functionalization and matrix structure selection}

\author{
Weiyu Dou, ${ }^{a}$ Jing Wang, ${ }^{b}$ Zhikan Yao, ${ }^{\text {ab }}$ Wei Xiao, ${ }^{c}$ Man Huang ${ }^{c}$ and \\ Lin Zhang (D) *ab
}

\begin{abstract}
Hemoperfusion has emerged as an admirable adjuvant treatment for some severe diseases and autoimmune diseases with favorable therapeutic effects because it can realize the specific removal of pathogenic factors existing in the blood of patients based on adsorption between pathogenic factors and ligands. Advances in natural and synthetic polymers, biomimetic coating and novel adsorbent fabrication technologies have led to the development of clinical applications of hemoperfusion. In this review, the history of hemoperfusion is traced, and the performance on common materials such as activated carbon, inorganic porous materials and polymers is evaluated. The functionalization methods of hemoperfusion pristine materials containing surface coating and surface grafting are introduced and compared. Matrixes with both traditional and novel structures are systematically summarized in detail. In addition, the indispensability for high-performance hemoperfusion devices is also highlighted, which could fill the gap of overview in materials science and serve as a bridge between medical professionals and scientists for future hemoperfusion development.
\end{abstract}

\section{Introduction}

${ }^{a}$ Zhejiang Key Laboratory of Smart Biomaterials, College of Chemical and Biological Engineering, Zhejiang University, Hangzhou, 310027, P. R. China. E-mail: linzhang@zju.edu.cn

${ }^{b}$ Ningbo Research Institute, Zhejiang University, Ningbo, 315100, P. R. China ${ }^{c}$ Critical Care Department, Second Affiliated Hospital, School of Medicine, Zhejiang University, Hangzhou 310027, P. R. China
The presence of some pathogens in the bloodstream, when exceeding the self-metabolic capacity under certain conditions, can often lead to illness such as sepsis, organ failure, severe intoxication, autoimmune diseases, etc. ${ }^{1-4}$ It has been demonstrated that extracorporeal blood purification could remove such substances from blood, improve outcomes of patients,

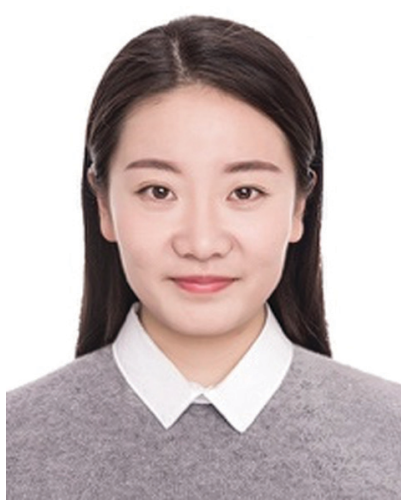

Weiyu Dou
Weiyu Dou is a PhD student at the Zhejiang Key Laboratory of Smart Biomaterials, College of Chemical and Biological Engineering, Zhejiang University, under Prof. Zhang's supervision. Her research currently focuses on high performance affinity membranes for whole blood purification in the treatment for sepsis.

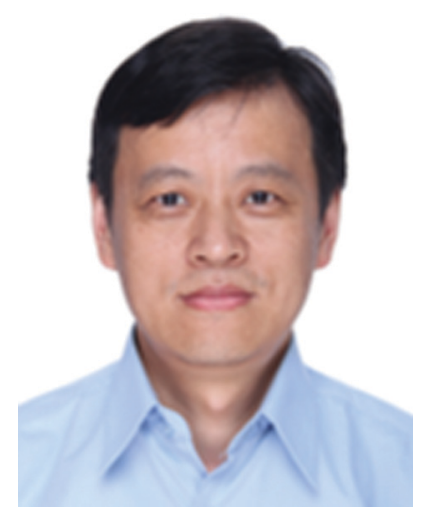

Lin Zhang
Prof. Lin Zhang obtained his BS degree in chemical engineering from Nanjing University of Chemical Technology (i.e. Nanjing Tech University) and his $P h D$ in chemical engineering from Zhejiang University. His research interests include application of membrane technology in biomedicine, advanced reverse osmosis/ nano-filtration membrane material design and membrane preparation, application of membrane technology in unconventional water source development and resource treatment. 


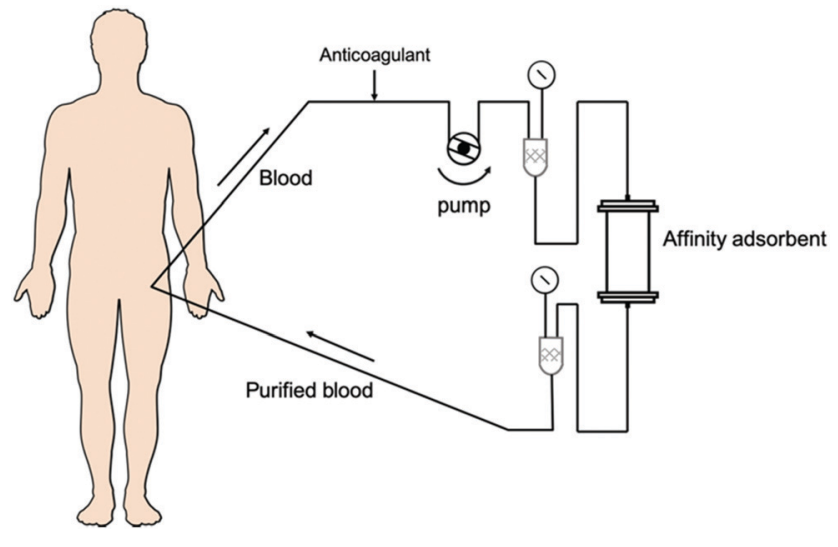

Scheme 1 Schematic illustration of direct hemoperfusion.

and even cure the diseases. ${ }^{5,6}$ Based on the mechanism of adsorption, hemoperfusion (as shown in Scheme 1) has a unique ability to efficiently adsorb molecules with larger molecular weight and/or high protein-binding affinity, which has been defined as the most useful method for blood purification. ${ }^{7}$

The capability of hemoperfusion depends on the adsorbents, which requires the adsorbent materials with good blood compatibility, adsorption selectivity, mechanical strength and sterilization resistance (thermal stability). Over the past few decades, most of the attempts were made to couple hemoperfusion technology with other blood purification technologies instead of using hemoperfusion alone to obtain better treatment efficiency. To develop a more advantageous hemoperfusion device for an intractable disease, material-based innovation and pathogenic-mechanismbased ascertainment is necessary. Therefore, interdisciplinary research studies on material science and medicine are critical. This review gives particular attention to the materials and matrix structure of hemoperfusion adsorbents that have commercial use and/or on laboratory research with potential clinical applications.

\section{Materials of hemoperfusion}

Since the materials determine the structure and function of the adsorbents, the development of materials is particularly significant. As shown in Fig. 1, the hemoperfusion materials have gone through three stages, from activated carbon to inorganic porous materials, and for now, polymers. The iteration from activated carbon to polymers indicates the demand for structure designability and hemocompatibility in hemoperfusion adsorbent.

\subsection{Activated carbon}

Activated carbon is usually used in aqueous solution purification, detoxification and drug poisoning treatment due to its large internal surface (as high as $2500 \mathrm{~m}^{2} \mathrm{~g}^{-1}$ ) and satisfactory adsorption property. In 1964, Yatzidis et al. ${ }^{8}$ first used activated carbon produced from natural raw materials as an adsorbent to remove creatinine, urate, phenols, salicylates, barbiturates, and glutethimide, which pioneered in the clinical application of hemoperfusion. The adsorption action of activated carbon was

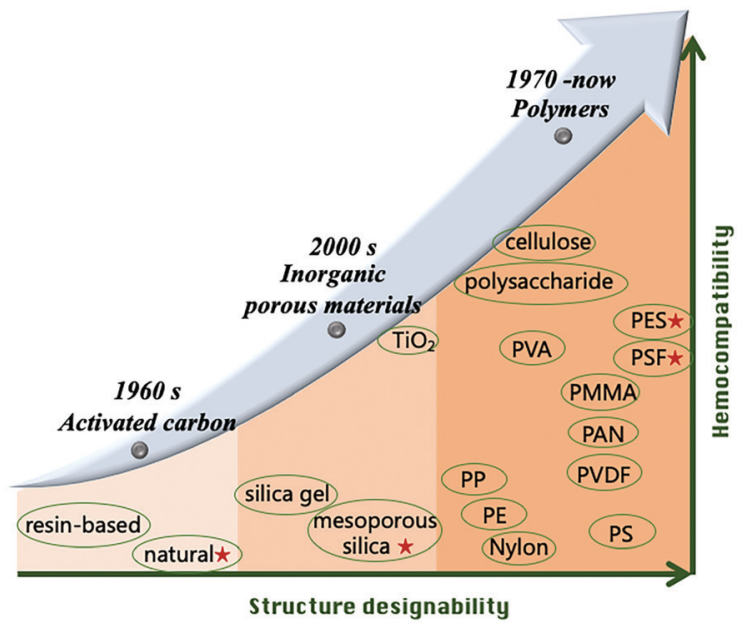

Fig. 1 The developing road map of hemoperfusion materials. The pentagrams represent the most researched materials in each type.

later supported by Dunea and Kolff, ${ }^{9}$ who found the same reduction in urate and creatinine levels. Similarly, Hagstam et al. ${ }^{10}$ and De Myttenaere et al. ${ }^{11}$ observed satisfactory removal rates of phenobarbitone and glutethimide. However, microscopical examination from Hagstam's group showed activated carbon particles could be deposited in several organs, indicating the granular activated carbon was not safe as a hemodetoxifier. Moreover, a controlled study of 137 patients with fulminant hepatic failure showed no survival benefit to activated carbon hemoperfusion, which made activated carbon's efficacy controversial. ${ }^{12}$ Although powdered/granular activated carbon has advantages such as low cost, wide range of applications and great detoxification effect, their intrinsic poor selectivity, low removal efficiency, the side effects derived from its rough surface in contact with blood, and the deposition of carbon debris in organs impede further application in hemoperfusion. ${ }^{13}$ It has been demonstrated that the poor biocompatibility of activated carbon is related to its rough surface. Therefore, making activated carbon with a smooth surface can be a useful method to improve the safety in medical treatment. ${ }^{13}$ To reduce the surface roughness of activated carbon, the activated carbon encapsulation technology was applied (shown in Fig. 2). ${ }^{14,15}$ Although this method avoids debris from leaving activated carbon, the nanoand mesopores of activated carbon were also blocked after encapsulation. As a result, this method reduces the adsorption property of activated carbon which depends on abundant nano-/mesopores. ${ }^{16}$

To overcome the side effects of natural activated carbon caused by the rough surface, activated carbon manufactured from other sources has become an alternative for adsorption materials. Jacek et al. ${ }^{17}$ found that resin-based activated carbon obtained from waste ion exchange resin gave excellent results in the removal of small sized molecules, which paved a new way to manufacture activated carbon with a smooth surface. However, the results showed that the actual adsorption capacity, which relates to the bottle-like pore structures of resin-based activated carbon, is less than the theoretical adsorption capacity. 

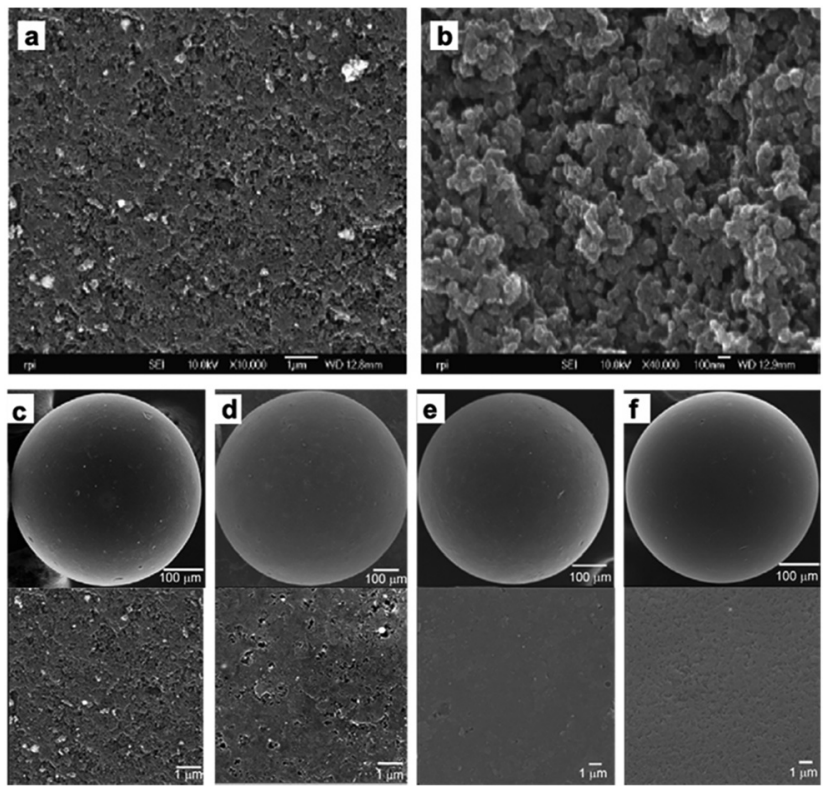

Fig. 2 SEM images of uncoated and coated activated carbon beads. (a-c) Uncoated beads (surface (a and c); cross-section (b)), (d) PMMA-coated beads, (e) PMMA-chitosan-coated beads, and (f) PMMA-chitosanheparin-coated beads (middle panel, low magnification; bottom panel, high magnification). Reproduced with permission from ref. 16 (Copyright 2012, American Chemistry Society.)

It has been proved to be a common phenomenon in resin-based carbon. ${ }^{18}$ Overall, the trade-off between the adsorption property and biocompatibility made the activated carbon-based materials no longer preferred for hemoperfusion.

\subsection{Inorganic porous materials}

Another carbon-based material, graphene, has also been applied in the hemoperfusion field, especially for bilirubin adsorption. The hemoperfusion materials suffer from the irregular pore structures of activated carbon materials, while graphene-based beads showed a good macro-mesoporous structure, high adsorption capacity and fast adsorption rate for bilirubin. ${ }^{19,20}$

Silica-based materials, $\mathrm{TiO}_{2}$ and porous glass were once thought to be the important substitutes of activated carbon materials for hemoperfusion. Mesoporous silicas, which have a high surface area, uniform pore size and abundant $\mathrm{Si}-\mathrm{OH}$ groups, have been used as adsorbents for medicine storage and targeting therapy. ${ }^{21,22}$ Shi et al. first used mesoporous silica in hemoperfusion for toxins removal. ${ }^{23}$ To illustrate the influence of the surface charge properties of silica on the adsorption ability, the toxin adsorption capacities of both bare commercial silica (SBA-15, $\mathrm{Si}-\mathrm{OH}$ groups, negative charge) and amine-grafting silica $\left(-\mathrm{NH}_{2}\right.$ groups, positively charged) were tested (Fig. 3). The results showed that both bare and amine-grafted mesoporous silica possess satisfied adsorption capacities for bilirubin and uric acid, but neither could adsorb creatinine nor phenobarbital. Similarly, Sun et al. synthesized well-ordered bio-functional mesoporous silica material (amine/methyl modification SBA-15) with platelet
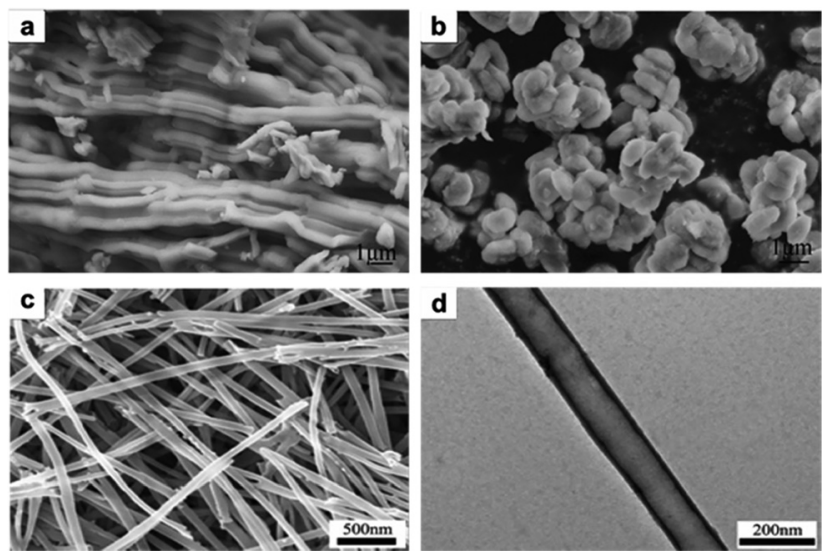

Fig. 3 SEM images of (a) SBA-15, (b) amine/methyl-modified SBA-15 with platelet morphology, and (c) silica nanotubes. (d) TEM image of nanotubes. Reproduced with permission. ${ }^{24,26}$ Copyright 2011, Elsevier ( $a$ and b) and IEEE (c and d), respectively.

morphology for bilirubin removal. ${ }^{24}$ This silica material exhibits high bilirubin clearance and high adsorption selectivity for bilirubin against albumin. Both Sun and Shi highlighted the reusability of mesoporous silica. Sun's hemolysis assay results also showed that the pure and bio-functional SBA-15 caused serious hemolysis of red blood cells. Overall, for safety reasons, the hemocompatibility rather than the reusability of hemoperfusion materials should be considered a priority.

Silica gel, formed by aggregating sodium silicate, is another important silica-based material. It is full of silanol groups on the surface, which is the basis for surface chemical modification. The reversed-phase silica gel possesses higher medicine removal efficiency from plasma compared to Amberlite ${ }^{\circledR}$ XAD-4 and coated-activated carbon. ${ }^{25}$ However, evident thrombocytopenia and leukopenia were noted during the hemocompatibility test. Silica nanotubes were also used as an affinity matrix material with an arginine immobilization-possessed good reusable performance and excellent bilirubin adsorption capacity (shown in Fig. 3). ${ }^{26}$ Nevertheless, this silica material is difficult to apply industrially and has been easily replaced by polymer-based nanomaterials due to its template based synthesis method. Besides, no silica-based materials in the application of hemoperfusion have been reported.

$\mathrm{TiO}_{2}$ is another significant inorganic biomedical material with good biocompatibility, which has attracted considerable attention for its application in hemoperfusion, as the large specific surface area (often 1000 times higher than its geometric area) of the mesoporous anatase $\mathrm{TiO}_{2}$ films allows high levels of hemoglobin adsorption. ${ }^{27}$ As a typical semiconductor, $\mathrm{TiO}_{2}$ also possesses good photocatalytic activity, which could potentially endow the self-sterilizing property as well as the photocatalytic decomposition capacity of the material to the adsorbed bilirubin. Combining the great adsorption capacity with the excellent semiconductor properties of $\mathrm{TiO}_{2}$, Si et al. ${ }^{28}$ showed the great adsorption behavior of bilirubin with a nanocrystalline $\mathrm{TiO}_{2}$ film and presumed that the nanocrystalline $\mathrm{TiO}_{2}$ could photo-catalytically decompose the adsorbed 

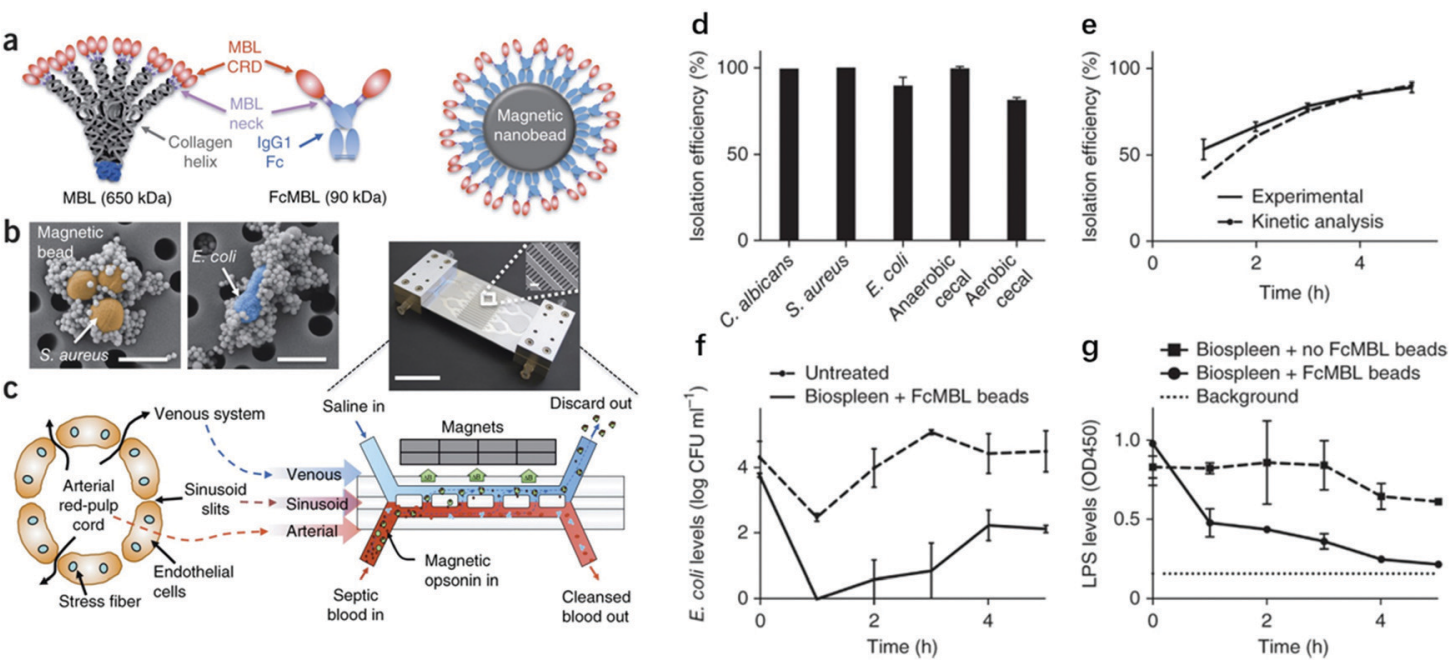

Fig. 4 Magnetic opsonin and biospleen device. Reproduced with permission from ref. 29. Copyright 2014, Springer Nature.

bilirubin. Yet, the in situ decomposition of bilirubin is just beneficial for recycling and shows no improvement in the removal of pathogenic substances.

Recently, a micromagnetic-microfluidic-combined device inspired by the microarchitecture and pathogen cleaning ability of the spleen has been developed to cleanse the pathogen from a sepsis patient's blood. ${ }^{29}$ The device is composed of magnetic nanobeads coated with a genetically engineered version of human mannose binding lectin (MBL) that could bind to a wide variety of pathogens (Fig. 4a and b). This fluidic device simulated the slits filtration process between adjacent endothelial cells of the spleen. The pathogens can be cleared by magnets (Fig. 4c). The multiple pathogens isolation efficiency and depletion of E. coli and lipopolysaccharide (LPS) indicate the great application potential in sepsis hemoperfusion (Fig. 4d-g).

Overall, although inorganic materials show great universal reusability, they are not prioritized for hemoperfusion due to their high cost of production, limited structural design possibility, and passable pathogenic substance removal efficiency.

\subsection{Polymeric materials}

Polymeric materials show high suitability for hemoperfusion compared with activated carbon and inorganic materials. Remarkable functions and stability under the constraints of the physiological environment are the main characteristics of hemoperfusion polymeric materials. In addition, biofunctionality and biocompatibility are the basic requisites, as well as the main basis for evaluating whether a polymeric material has potential in hemoperfusion application. The application of polymeric materials in hemoperfusion could be traced back to 1976, when Rosenbaum et al. first used ion exchange resin (Amberlite ${ }^{\mathbb{R}}$ IR-120) to remove urea nitrogen and blood ammonia. They found the exchange resin had a good clearance effect on unbounded bilirubin and barbiturates, but the possibility of damaging the platelet was tricky. ${ }^{30}$ Later, according to the destruction of electrolyte balance in blood caused by the exchange reaction between the ion exchange resins and the electrolyte, the application of ion exchange resins in hemoperfusion has been restricted. Later on, synthetic resins or synthetic polymer materials, which mainly rely on polar and non-polar interactions, began to be used in hemoperfusion. During the synthesis of polymers, specific adsorption groups could be introduced into the resin by molecular design or surface modification. The tailored resin materials show good chemical stability without any particle shedding, which has gradually become the focus of the specific adsorbents.

Natural and synthetic polymers are two types of polymeric materials that are used in hemoperfusion (Table 1). Natural polymers include polysaccharide, cellulose and their derivatives. These materials always show great biocompatibility, owing to the similar components and structure shared with substances in vivo. Among those natural polymer materials, cellulose-based materials have attracted extensive attention due to their availability. However, the adsorption selectivity of cellulose-based materials is not advantageous. ${ }^{31,32}$ To meet the requirement of treating diseases more precisely, modification of natural polymer materials is required. Later, synthetic polymer materials are introduced to the application of hemoperfusion due to the wide variety of them and the ease of large-scale production. The common synthetic polymer adsorbents are produced from hydrocarbon polymers (polyethylene (PE), polypropylene (PP) and polyacrylonitrile (PAN)), aromatic copolymers (polysulfone (PS) and polyethersulfone (PES)), aliphatic polyamides (nylon-6 and nylon66), and some special polymers, such as polyvinylalcohol (PVA) and polymethylmethacrylate (PMMA). Among them, aromatic polymers and the polyamides have received more attention, due to their modifiable containments of functional end-groups. However, these two kinds of polymers show a high non-specific binding ability, presumably due to strong hydrophobicity. The only synthetic hydrophilic polymer, PVA, didn't show better hemocompatibility because of its blood dissolvability.

Overall, the common deficiency of bare activated carbon, inorganic porous materials, and most polymers is their intrinsically, non-biologically inertness, which is related to its 
Table 1 Polymer hemoperfusion materials

\begin{tabular}{|c|c|c|c|c|c|}
\hline Type & Classification & Example & $\begin{array}{l}\text { Unit structure } \\
\text { (polymer) }\end{array}$ & Advantages & Drawbacks \\
\hline \multirow{9}{*}{$\begin{array}{l}\text { Activated } \\
\text { carbon }^{8,17} \\
\text { Inorganic } \\
\text { porous } \\
\text { materials }\end{array}$} & - & - & - & $\begin{array}{l}\text { High specific area, } \\
\text { low cost }\end{array}$ & Poor hemo-compatibility \\
\hline & Graphene $\mathrm{e}^{19,33}$ & & - & $\begin{array}{l}\text { Regular pore } \\
\text { structure }\end{array}$ & High cost \\
\hline & Silica-based & Mesoporous silica $^{24}$ & - & Reusability & Poor modifiability \\
\hline & materials & & - & Reusability & $\begin{array}{l}\text { Poor adsorptive } \\
\text { selectivity }\end{array}$ \\
\hline & & Silica gel ${ }^{25,26}$ & - & Hemo-compatibility & $\begin{array}{l}\text { Difficulty in } \\
\text { industrialization }\end{array}$ \\
\hline & $\mathrm{TiO}_{2}^{27,28}$ & & - & Reusability & Poor modifiability \\
\hline & $\begin{array}{l}\text { Magnetic } \\
\text { nanobeads }\end{array}$ & & - & High specificity & Limited clinical data \\
\hline & & Chitosan $^{34-36}$ & & Hemo-compatibility & Degradability \\
\hline & Polysaccharide & & & & \\
\hline \multirow[t]{6}{*}{$\begin{array}{l}\text { Natural } \\
\text { polymer }\end{array}$} & & Chitin $^{37,38}$ & & Hemo-compatibility & Poor machinability \\
\hline & Cellulose $^{31,39,40}$ & & & Hemo-compatibility & Degradability \\
\hline & & Polyethylene ${ }^{41}$ & & Bioinertia & Poor structure designability \\
\hline & & Polypropylene $^{42}$ & & Modifiability & Poor hemo-compatibility \\
\hline & $\begin{array}{l}\text { Hydrocarbon } \\
\text { polymers }\end{array}$ & Polyacrylonitrile $^{43}$ & & Modifiability & Poor hemo-compatibility \\
\hline & & $\begin{array}{l}\text { Polyvinylidene } \\
\text { fluoride }^{44}\end{array}$ & & Structure designability & Poor hemo-compatibility \\
\hline \multirow{6}{*}{$\begin{array}{l}\text { Synthetic } \\
\text { polymer }\end{array}$} & & Polysulfone ${ }^{45}$ & & $\begin{array}{l}\text { Structure designability, } \\
\text { hemo-compatibility }\end{array}$ & Poor modifiability \\
\hline & $\begin{array}{l}\text { Aromatic } \\
\text { copolymers }\end{array}$ & Polyethersulfone $^{46}$ & & $\begin{array}{l}\text { Structure designability, } \\
\text { hemo-compatibility }\end{array}$ & Poor modifiability \\
\hline & & Polystyrene $\mathrm{e}^{42}$ & & Structure designability & Poor hemo-compatibility \\
\hline & $\begin{array}{l}\text { Aliphatic } \\
\text { polyamides }^{47,48}\end{array}$ & & & Low cost & Poor modifiability \\
\hline & & $\begin{array}{l}\text { Polyvinyl } \\
\text { alcohol }^{40,49}\end{array}$ & & Hemo-compatibility & $\begin{array}{l}\text { Poor modifiability, } \\
\text { poor structure designability }\end{array}$ \\
\hline & Other & $\begin{array}{l}\text { Poly-methyl- } \\
\text { methacrylate }\end{array}$ & & $\begin{array}{l}\text { Hemo-compatibility, } \\
\text { modifiability }\end{array}$ & Poor structure designability \\
\hline
\end{tabular}

Reproduced from references.

hydrophobicity and specific pathogen adsorption capacity. Thus, the first step for many investigators is to apply those hydrophobic synthetic polymers for hemoperfusion, and then introduce a hydrophilic substituent into the materials. The hydrophilic substituents could become the carrier for the ligand or the anticoagulation. The modification and ligand grafting will be reviewed in the next section.

\section{Functionalization of hemoperfusion materials}

As they are in contact with blood for a long time (or temporarily), the materials must be fully compatible with the biological environment. That is to say, the body can't undergo any biological reactions such as toxicity, inflammation, carcinogenesis, and thrombosis. Thus, the surface of the hemoperfusion materials should be biologically inert. However, the biocompatibility of activated carbon and most synthesized polymer materials was not sufficient. Controlling and improving the surface properties of materials is essential to improve and promote favorable interactions and inhibit adverse interactions between the surface of materials and pathogens. Besides, the curative efficiency of hemoperfusion depends critically on the performance and hemocompatibility of the adsorbents. Research on hemoperfusion materials also focuses on improving hemocompatibility and adsorption specificity. ${ }^{51}$ Therefore, modification of hemoperfusion materials is 
necessary. This is usually achieved by surface coating and surface grafting.

\subsection{Surface coating}

Side effects shown from bare activated carbon and synthesized materials include thrombosis, clotting, activated carbon embolism, leucopenia, pyrogen reactions, and nonspecific blood protein adsorption, give researchers concern regarding the direct use of bare materials in a blood environment. ${ }^{52-54}$ To construct a defect-free modified layer on the surface of materials eliminating the disadvantages of the bare material, and to enhance the biocompatibility of hemoperfusion materials and improve the adsorption properties, surface coating is regarded as a simple and effective method.

Chang used a micro-encapsulation method in an activated carbon particle coating, which remarkably reduced the adverse reactions between bare activated carbon particles and blood composition. ${ }^{55}$ Inspired by Chang's work, Kolff et al. pointed out that hydrophilic coating materials would be a good choice for similar interfacial energy as they mimic vascular lining. ${ }^{56}$ In subsequent decades, surface coating technology based on hydrophilic hydrogels has been vigorously developed. Widdop et al. coated an acrylic hydrogel on the surface of commercial XAD-2 and XAD-3 resin for dog's medicine poisoning treatment, which eliminated charcoal embolism. ${ }^{57}$ Similarly, Vale et al. used synthetic hydrogel-coated activated carbon and cured four clinical medicine overdose or poisoned patients out of six patients. ${ }^{58}$ To further optimize the modified materials, a large number of coating materials such as cellulose nitrate, albumin-collodion, cellulose acetate, and polyamide have been evaluated by Chang's group. ${ }^{59-61}$ Results showed that only albumin-collodion could maintain an acceptable adsorption capacity without marked falling in the platelet level occurring simultaneously, which is considered to be related to the anti-adhesion properties of the albumin film surface on the platelets.

It has been proved that anti-adhesion property is also an important factor for biocompatibility. ${ }^{62-64}$ Thus, anti-adhesion modification of materials have received widespread attention in the hemoperfusion field. Zwitterionic-based materials, which are famous for their excellent hydrophilicity and antiadhesion property, were used as surface coating materials on hemoperfusion materials. ${ }^{65-71}$ Coated by poly-carboxybetaine (pCB) and poly(carboxybetaine methacrylate) hydrogel (pCBMA) in the research studies of Zhang et ll $^{72}$ and Qi et al. ${ }^{73}$ respectively, the modified activated carbon demonstrated that the adsorbents were highly hemocompatible with fresh blood, while the adsorbing ability of the pCBMA coating was much better than the $\mathrm{pCB}$ coating. Besides, the hydrophilic polymer brushes were also used as surface coating materials due to their resistance to protein and cell adsorption. Schilke et al. ${ }^{74}$ showed tethering of the antimicrobial peptide WLBU2 on pendant hydrophilic polymer brushes coating chains enhanced its ability to capture endotoxin in blood. With the development of a natural hydrophilic polymer, the biodegradable and vivo-existing polymer showed great potential in material modification to improve their stability, biocompatibility, pharmacokinetics, and thus biomedical functions. ${ }^{75,76}$
This is supported by Howell et al. ${ }^{53}$ and Linhardt et al. ${ }^{16}$ They coated activated carbon with dextran and chitosan respectively, which retained the meso/microporous structure while having little effect on the adsorption rate and equilibrium adsorption capacity, and showed great hemocompatibility. Liu et $a l .{ }^{77}$ prepared mussel-inspired polydopamine coated carbon fiber for blood detoxification. The polydopamine coating served as the middle functional layer, which significantly improved the hemocompatibility and provided functional groups for grafting bioactive ligands for the specific removal of different toxic substances.

Though the hemocompatibility of the adsorbents could be well improved by surface coating of hydrophilic and/or antiadhesion materials, the deterioration in adsorption capacity and/or adsorption selectivity is obvious..$^{57,58}$ Thus, novel modification materials which can show both great hemocompatibility and adsorption property are required. However, limited research exists on adsorption property-improved coating materials over the last several decades. Rimmelé et al. and Hattori et al. demonstrated that PEI-coated AN69 (a commercial hemodialysis membrane) membranes have a higher LPS adsorption capacity than AN69 membranes, which is related to the high amount of cationic functional groups of PEI. ${ }^{78,79}$ In addition, a more advanced peptide nanosheet coating on polypropylene (PP) nonwoven fabrics was proposed by Uji et al. ${ }^{80}$ These peptide nanosheets have two faces, one for phenylboronic acid to connect to site-oriented antibodies to remove regulatory $\mathrm{T}$ cells specifically, and the other for a photoactivable radical generator to react with PP fiber to improve the compatibility of the PP fiber. This method established a strategy of highly biocompatible surface coating on pristine hemoperfusion materials, which pioneered the research of peptide and protein coating materials. Whether it is an abiological or a biological coating, both can achieve significant improvement in hemocompatibility. The adsorption of coating to a pathogen is unspecific and the excessive removal of useful substances in blood is unavoidable. Therefore, developing novel polymer coatings with a better performance is still highly desired.

\subsection{Surface grafting}

Elucidation of the modification method for hemoperfusion adsorbent by surface coating points out that low adsorption selectivity remains a limitation for accurate treatment, indicating the necessity to obtain a modification method to improve the adsorption selectivity. By modifying a hemoperfusion agent with a surface grafting method, a specific adsorption capacity of toxic substances could be endowed, exhibiting great potential for precise treatment of diseases through the modified hemoperfusion agent. Raw materials with abundant reactive groups could be modified by one-step surface grafting to improve biocompatibility and endow the specific removal capacity of toxic substances. Based on interactions between the grafted ligands and the adsorbates, the grafted ligands could be divided into two types, including biological affinity ligands and physicochemical affinity ligands. Both of them have not been clearly defined. Usually, the binding of biological affinity ligands and their receptors requires 
conformational matching, and the binding force generally includes more than two intermolecular forces. On the other hand, physicochemical affinity ligands bind receptors through electrostatic and hydrophobic interactions, and they don't have specific conformational matching requirements. It is worth mentioning that when ligands or toxic molecules are large, then spacers become necessary. Spacers can reduce steric hindrance between ligands and toxic molecules, resulting in an increase in the adsorption capacity of the adsorbent. ${ }^{40}$ However, since spacers are relatively monotonous, they will not be repeated in here.

3.2.1 Biological affinity ligands. Biological affinity ligands usually refer to biomolecules with good selectivity and high biocompatibility. ${ }^{81}$ Common biological affinity ligands are composed of protein, peptide, amino acid, and some other biomimetic molecules. Two typical applications of biological ligands for the treatment of specific diseases are polymyxin B to bind endotoxin in the treatment of sepsis ${ }^{81}$ and protein $\mathrm{A}$ to bind anthrax toxin. ${ }^{82}$ Polymyxin $\mathrm{B}$ is a cyclic cationic polypeptide antibiotic derived from Bacillus polymyxa that can bind and neutralize endotoxin. ${ }^{83}$ Benefiting from its high endotoxin affinity, Toray immobilized polymyxin B on the polystyrene fiber to fabricate hemoperfusion cartridge for the treatment of sepsis. ${ }^{84}$ Unfortunately, polymyxin B in vivo resulted in nephrotoxicity and neurotoxicity. A recent publication pointed out the controversy of the therapeutic effect of this cartridge against other published research, ${ }^{85}$ which limits its extracorporeal application as the hemoperfusion ligand. To remove endotoxin from blood, the L-serine grafted PVDF affinity membrane prepared in our group displayed good hemocompatibility, high endotoxin selectivity and removal efficiency. ${ }^{44}$ Additionally, adsorbents packed with PSF-Ser have also been tested. The results showed the effective removal capacity of endotoxin from human plasma as well. ${ }^{45}$ In these two typical examples, coagulation is always avoided by extra injection of heparin, which is a highly sulfated linear polysaccharide anticoagulant. ${ }^{86}$ To avoid the risk of extra injection of heparin, Wang et al. ${ }^{87}$ immobilized heparin on polystyrene microspheres with L-phenylalanine as a ligand (Ps-Hep-Phe) through an EDC/NHS coupling method to simultaneously remove endotoxin and prevent anticoagulation.

Another mature application of a biological ligand in hemoperfusion is the treatment of bilirubinemia. It has been demonstrated that acute liver failure is related to the increase of serum bilirubin. Therefore many efforts have been put into highly efficient removal of bilirubin from blood. ${ }^{88}$ Zhang et al. immobilized lysine into chitin-based microspheres to obtain lysineimmobilized chitin/carbon nanotube microspheres, which improved the biocompatibility and bilirubin adsorption capacity. $^{38}$

Except for ligands like antibiotics, amino acids and proteins, $\mathrm{Yu}$ et al. creatively grafted DNA on immune adsorbents to treat patients with systemic lupus erythematosus, nephritis and central nervous system symptoms. ${ }^{89}$ DNA nanostructures can be an effective intermediate for immobilizing biomolecules due to their high level of controllability and flexibility to create the desired fine nanostructures through precision "bottom-up" assembly. ${ }^{90}$ Accordingly, novel nucleic acid-based ligands, aptamers, attracted wide attention for their high specificity and stability under physiological conditions compared to protein-based ligands. ${ }^{91}$ Aptamers with specific structures could be selected or designed by computers and synthesized with high reproducibility and purity. Wang et al. reported for the first time the immobilization of hepatitis B virus surface antigen (HBsAg)-binding aptamers for the removal of HBsAg from patients' serum. Recently, an aptamer for an endotoxin biosensor was screened, which showed great potential for developing a novel sepsis hemoperfusion cartridge. ${ }^{92}$

The amounts of immunosuppressants derived from a signal transduction molecule or signal molecule receptor in vivo have shown excellent treatment efficacy for autoimmune diseases. Inspired by this, innovation of novel biological ligands derived from signal transduction molecules and signal molecule receptors in severe disease would largely depend on further clarification of the pathogenic mechanism.

3.2.2 Physicochemical affinity ligands. Physicochemical affinity ligands usually refer to synthetic ligands with good stability and low cost. ${ }^{81}$ They show good resistance to biological degradation and could be readily immobilized to generate adsorbents with a highly selective affinity for their complementary molecules. ${ }^{93}$ It has been indicated that amino groups containing adsorbents could remove bilirubin by electrostatic interaction. Inspired by the work of Zhao's group, ${ }^{94}$ Wang et $a l .{ }^{43}$ reported the fabrication of branched polyethylenimine (PEI) grafted electrospun polyacrylonitrile (PAN) fiber membranes with great adsorption performance towards bilirubin. Similarly, the presence of amino groups in chitosan makes it suitable for modification. Fu et al. introduced poly(acrylic acid) (PAA) onto the cross-linked chitosan beads, which significantly improved both the low-density lipoprotein (LDL) binding capacity and selectivity. ${ }^{95}$ Differently, Yuan et al. designed three affinity ligands by computational simulation based on the molecular structure of Asp-Phe-Leu-Ala-Glu (DE5), which is related to uremia, and evaluated the removal effect for DE5 molecules. ${ }^{81}$ The designed ligands showed great selectivity and better adsorption capacity. Computer-aided analysis indicated that it is an optimal collaboration of coordination and hydrophobic interactions that contributed to the higher adsorption and selectivity, which provide a new strategy for understanding the adsorption mechanisms.

Overall, affinity, which is mainly determined by the strength and complexity of the interaction between ligands and adsorbates, can cause atoms and molecules to combine and stay combined. ${ }^{96}$ In the perspective of hemoperfusion, this combination is based on particular biological interactions. The appropriate ligand selection is based on a certain degree of knowledge and understanding of the nature of interactions between a ligand and the adsorbates. During the past few decades, enormous progress has been raised to understand the molecular basis of disease processes. The complicated intermolecular forces between pathogenic substances and receptors have been inspected. Hence, the biological ligands take advantage of complicated interaction forces, showing a superior potential as hemoperfusion ligands compared with 
physicochemical ligands. At the same time, technological advances in the genomics area and proteomics research increase the possibility of discovering and designing many biological molecules with desirable therapeutic functions.

\section{Matrix structure of materials in applied hemoperfusion components}

The preceding discussions focused on the types, modification and functionalization of hemoperfusion apparatus' matrix materials. To apply hemoperfusion devices to the blood system, they should be assembled with these materials. Here we summarize the main matrix structure of commercial hemoperfusion devices and highlight some novel material matrix structures that have potential for future hemoperfusion clinical use.

\subsection{Microspheres packed column}

The current microsphere hemoperfusion devices originated from an activated carbon particle packed hemoperfusion device which was a pioneer in extracorporeal blood adsorption. The original hemoperfusion device used activated carbon particles with high specific areas as fillers to enable uric acid removal. However, it is clinically inaccessible due to a plethora of adverse effects. ${ }^{97}$ The commercially packed microsphere columns for hemoperfusion are shown in Table 2. Novel kevlarbased composite gel beads for hemoperfusion were prepared by the interface assembly based on $\pi-\pi$ interaction showing superior mechanical strength, self-anticoagulation capability and robust adsorption capacities for diverse kinds of toxins, owing to the dual-network structure, heparin-mimicking gel structure and strong charge and $\pi-\pi$ interactions, respectively. ${ }^{33}$ The satisfactory adsorption capability and convenience without extra injection of heparin makes this method a potential strategy for future clinical chronic liver and chronic renal failure treatment. From the perspective of matrix structure and fluid dynamics, high porosity matrix materials, such as hollow fiber membrane and fibrous format, could be considered to have constant porosity. But in a packed bed, the porosity varies sharply near the wall since the packing geometry is interrupted there. ${ }^{98,99}$ Since blood is a non-Newtonian fluid, the accuracy of the microsphere-packed adsorbent's design and the flow distribution of blood within the sorbent particles is extremely important. Channels with different sizes commonly exist in inhomogeneous packed column, resulting in significant variation of blood flow velocity. The side effects correlated with the inhomogeneous distribution of blood flow have been pointed out. The treatment by particle packed column must be followed by pre-separating plasma and hemocyte (Fig. 5a). ${ }^{100}$ The region containing channels with a large diameter always show a poor utilization rate of the sorbent potential, reduction in adsorption performance and rapid saturation of the unit (Fig. 5b-d). ${ }^{101}$ Because of the complex requirements in design, the microsphere packed adsorbents are not preferred in extracorporeal blood adsorption treatment nowadays.

\subsection{Hollow fiber membrane}

Hollow fiber membranes are prepared through an extrusionphase transformation method, which have a tubular structure, and are widely used in hemodialysis for the removal of small molecules based on solute diffusion and convection in the aqueous system. Since the hollow fiber membrane pore size is relatively regular, the coagulation problem caused by the structure could be avoided. The early affinity hollow fiber membrane described by Sepracor' s group showed large inside diameters, and were packed with low fiber density, leading to large interstitial volumes. ${ }^{105}$ Compared to microsphere-packed adsorbents, this pack was inefficient. ${ }^{106}$ Novel hollow fiber types of hemoperfusion apparatuses have overcome this disadvantage by shrinking the diameters of fibers and micropores in the profile of a fiber. Nevertheless, fouling and high transmembrane pressure drop would occur when using hollow fiber membranes with small pore sizes due to the adhesion of cells or albumins. These would result in increasing resistance to flow and an increasing pressure drop inside the cartridge. Thus, pre-separation of plasma and blood cells is necessary. The geometry and fluid flow path of hollow fiber adsorbents are shown in Fig. 6. The transmembrane pressure (TMP), which could avoid clotting, is mainly determined by the length of fibers and the shear rate. ${ }^{106} \mathrm{~A}$ recently developed hollow fiber adsorbent (AN69 oXiris ${ }^{\mathbb{R}}$ ) for septic blood purification has adsorptive capacity for not only low-molecular-weight proteins (related to the large area) but also endotoxin and other negatively charged compounds due to a specific polymeric coating incorporated in the manufacturing process (Fig. 7). ${ }^{107}$ However, the electrostatic-based nonspecific adsorption would result in poor adsorption selectivity, which limits the utilization of this cartridge.

\subsection{Other forms}

To eliminate the intrinsic side effects of activated carbon materials, many efforts have been made to improve the packing form of them. Gong et al. reported a lotus root-type monolithic-activated carbon with a hierarchical pore structure for

Table 2 Examples, technical details, and studies for adsorbent columns

\begin{tabular}{|c|c|c|c|}
\hline Name & Material & Use & Reference \\
\hline CytoSorb $^{\circledR}$ & Cross-linked divinylbenzene/polyvinylpyrrolidone beads & Cytokine hemoperfusion & 102 \\
\hline Lixelle ${ }^{\mathbb{R}}$ & Porous cellulose beads & Cytokine hemoperfusion & 103 \\
\hline CPFA $^{\circledR}$ Bello & Reverse-phase styrenic polymer resin & $\begin{array}{l}\text { In multi-organ failure and/or sepsis CPFA } \\
\text { (Coupled plasma filtration and adsorption) }\end{array}$ & 104 \\
\hline
\end{tabular}

Reproduced from references. 
a

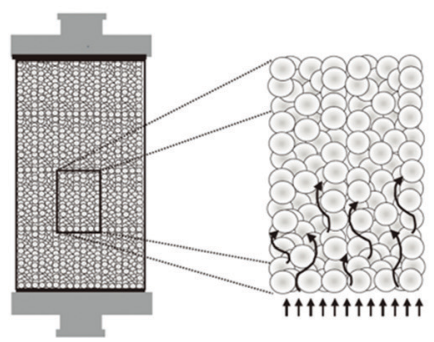

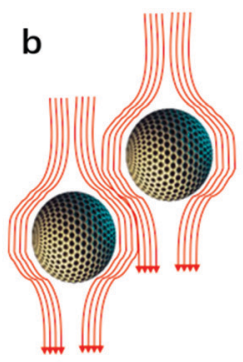

c

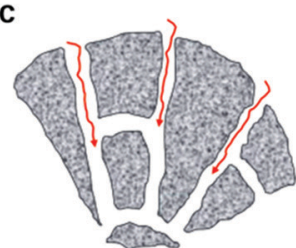

d

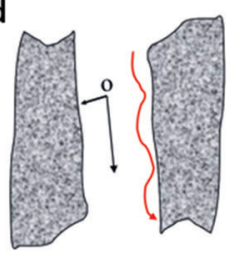

Fig. 5 (a) Flow distribution through packed microspheres. (b-d) Mechanism of mass transport from bulk solution to sorbent surface. (b) External (interphase) mass transfer of the solute by convection from the bulk fluid by diffusion through a thin film or boundary layer to the outer surface of the sorbent. (c) Internal (intraphase) mass transfer of the solute by pore convection from the outer surface of the adsorbent to the inner surface of the internal porous structure. (d) Surface diffusion along the porous surface and adsorption of the solute onto the porous surface. Reproduced with permission from ref. 100 and 101. Copyright 2000, SAGE Publications (a) and 2017, S. Karger AG (b-d), respectively.

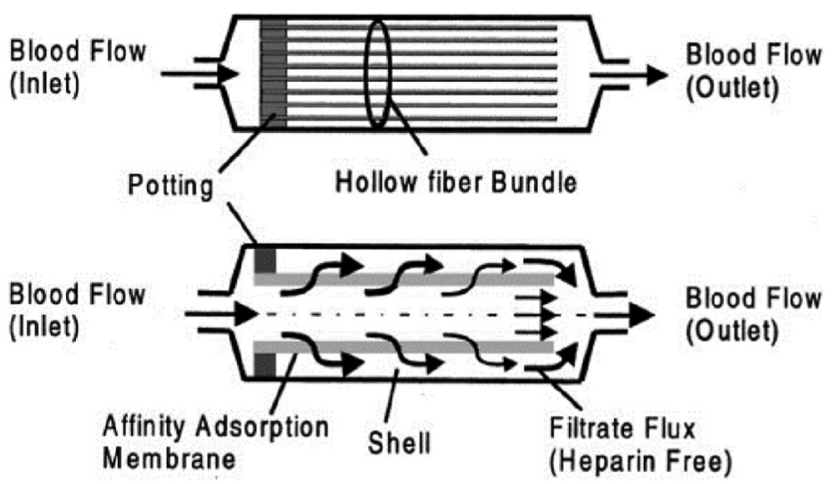

Fig. 6 Diagram and flow schematic of an open-ended transmembrane adsorbent. Reproduced with permission from ref. 106. Copyright 2000 , Elsevier.

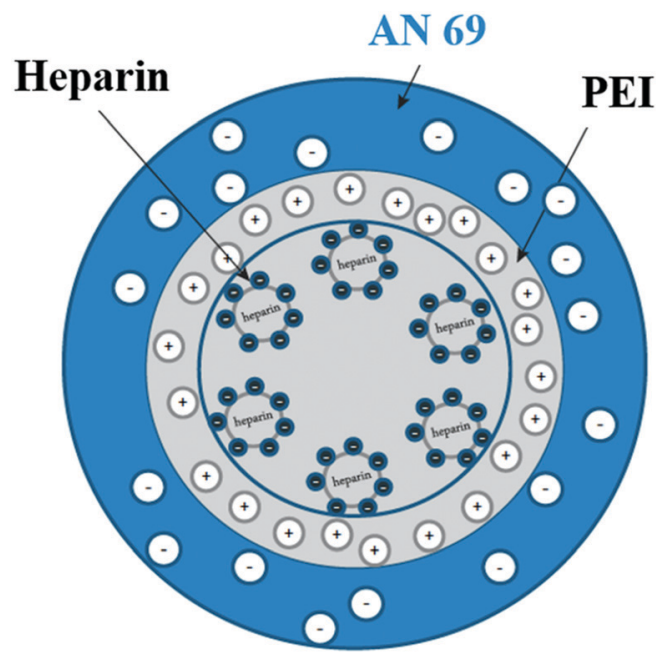

Fig. 7 Representation of an oXiris ${ }^{\circledR}$ hollow fiber. Reproduced with permission from ref. 108. Copyright 2018, S. Karger AG.

hemoperfusion derived from the husk (Fig. 8). ${ }^{109}$ The continuous channels in this activated carbon cartridge could reduce the pressure drop and avoid the detrimental collisions between the hemocytes and the adsorbents. After injection molding, the specific surface area decreased from $1000 \mathrm{~m}^{2} \mathrm{~g}^{-1}$ to $329 \mathrm{~m}^{2} \mathrm{~g}^{-1}$. The pores of micro, meso and macro sizes remained in the wall of the channels, which meant the incomplete avoidance of the collision between the blood cell and the beads.

Ronco et al. pointed out that adsorbents should have favorable kinetics and transport properties for the rapid adsorption of target solutes, which means the requisite of the adsorbents with excellent permeability. ${ }^{101}$ As mentioned above, the transmembrane pressure drop of the hollow fiber membrane is obvious. Fibrous materials with sub-microns or nanometer diameters show a large surface area, flexibility in surface functionalities, superior mechanical performance, and small pressure drop, making them one of the optimal candidates for clinical application adsorbents. ${ }^{110}$ Despite the diversity of the extracellular matrix structures caused by different biomacromolecules and various construction methods, a well-known feature of the native extracellular cytoplasmic matrix (ECM) is the fiber-staggered structure with nanoscale dimension. The development of thin fibrous carrier materials provides a way for industries to design hemoperfusion cartridges. The processing techniques such as template synthesis, ${ }^{111}$ self-assembly, ${ }^{112}$ melt spinning, ${ }^{42}$ elestrospinning, ${ }^{113}$ etc., have been used to manufacture the fabric. Among these processing techniques, melt spinning and electrospinning were adopted to produce the hemoperfusion adsorbents. The hemoperfusion cartridge manufactured by Toray Industry Inc., termed Toraymyxin ${ }^{\mathbb{R}}$ (Fig. 9), was produced by the melt spinning process. The cartridge consists of a polystyrene-based, fibrous adsorbent on which polymyxin B antibiotic is covalently immobilized as the ligands to adsorb endotoxins. ${ }^{42}$ On the other hand, in addition to the controversy of the treatment effect of Toraymyxin ${ }^{\mathbb{B}}$ mentioned above, the relatively rough fiber surface of the melt-spinning fibers are also adverse to blood constituents. Ronco and Klein pointed out that activated cells could be adsorbed by the Toraymyxin ${ }^{\circledR}$ fibers (Fig. 9d). ${ }^{114}$ The electrospun fibrous membranes are composed of stacks of nanofibers stretched by the electrostatic field and possess solid or porous structures, which share a similar structure with human tissues, thus, show better biocompatibility. As early as 1966 , Simon et al. ${ }^{115}$ patented an electrospinning apparatus that could produce relatively continuous, thin, 

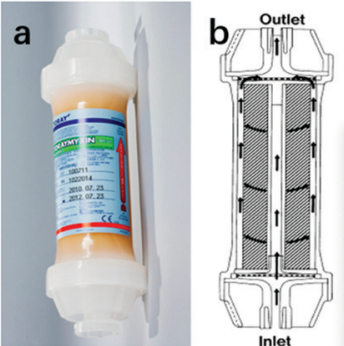

f

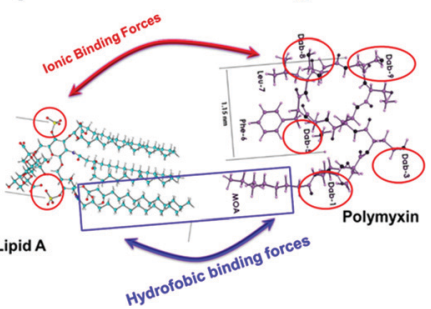

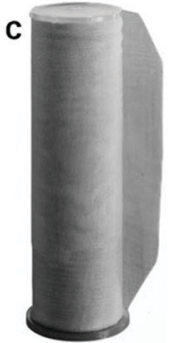
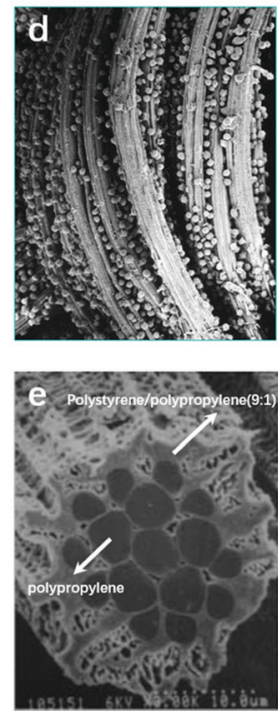

Fig. 9 Schematic diagram of Polymyxin B cartridge and endotoxin removal mechanism. (a and b) Schematic diagram of the blood flow within a Toraymyxin cartridge. (c-e) The cartridge containing polystyrenic fibers bound to polymyxin-B. (f) Lipopolysaccharide (LPS) binds to polymyxin with weak ionic forces and strong hydrophobic forces. Reproduced the permission from ref. 114 (Fig. 8a, d and f) and ref. 42 (Fig. 8b, c and e). Copyright 2014 (Fig. 8a, d and f), Springer Nature and 2003 (Fig. 8b, c and e), International Society for Apheresis, respectively.

and smooth fibers by controlling the viscosity of the solution. Hence, from a biological viewpoint, electrospun nanofibrous mats were a more promising material for hemoperfusion. ${ }^{116}$ To date, more than hundreds of polymers, primarily dissolved in solvents and partly heated into melts, have been successfully spun into ultrafine fibers using this technique. ${ }^{113}$ The schematic preparation process of the electrospinning nanofibrous membranes is displayed in Fig. 10(a). The usage of natural polymers in this technique could further improve hemocompatibility. Many scholars recently carried out research on electrospinning nanofibrous membranes as the matrix materials for hemoperfusion. The results showed better adsorption capacity and excellent

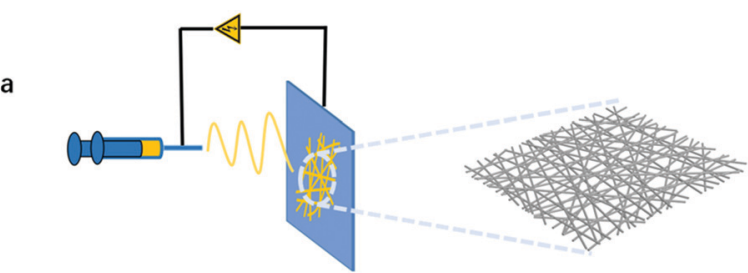

Electrospun
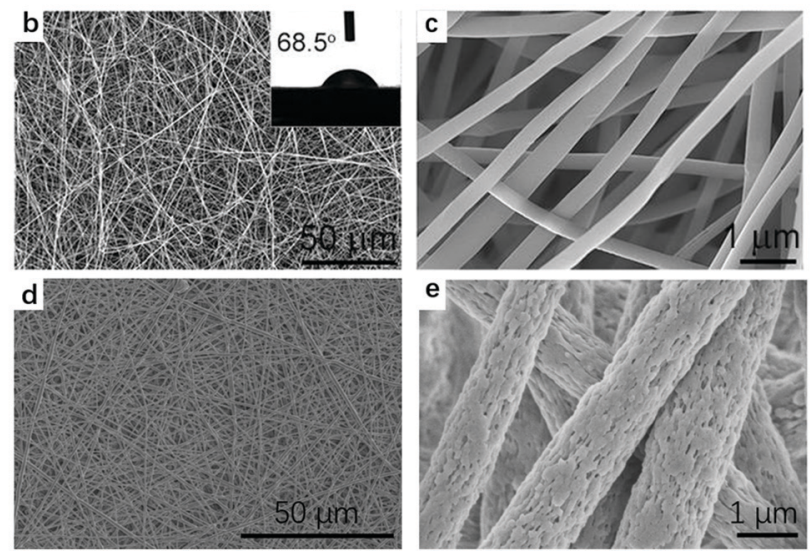

Fig. 10 (a) A schematic of the preparation process for the electrospinning nanofibrous membrane. (b and c) SEM images of the PAN electrospinning fibrous membrane. ( $d$ and e) SEM images of the PSF electrospinning fibrous membrane. Reproduced with permission from ref. 118 (Fig. 9a) and ref. 43 (Fig. 9b and c), respectively. (Copyright 2021 (Fig. 9a) and 2018 (Fig. 9b and c), Elsevier, respectively).

selectivity. The SEM images of PAN and PSF electrospinning fibrous membranes are shown in Fig. 10(b-d). ${ }^{43,46,117}$ Even though much effort has been made to research electrospun fibers as hemoperfusion matrix materials, the clinical trials and even commercial manufacture are lacking.

\section{Summary and perspectives}

Since the first clinical use of adsorbents in patients in 1958, numerous researchers have dedicated their efforts to the 
innovation of adsorbents, and hemoperfusion has become a normalized therapy for critical illnesses. Over the past several decades, in general, remarkable improvement in avoiding the side effects of pristine materials in hemoperfusion was achieved. The applications of polymeric materials and modified materials in hemoperfusion have greatly improved the treatment of many diseases. However, applications of hemoperfusion devices for the treatment of specific diseases are still lacking. Further elucidation of the pathogenic mechanism and the development of specific ligands are still required.

In summary, the design of hemoperfusion adsorbents should follow the following principles: (1) proper materials that possess proper structural designability and hemocompatibility. (2) Preferable functionalization methods that enable better hemocompatibility and pathogen-specific binding ability of the adsorbents. (3) Efficient packing ways with high specific area and suitability of whole blood perfusion. In future, the adsorbents composed of high hemocompatibility materials and specific ligands would be the optimal choice for critical illness treatment owing to the feasibility of whole blood perfusion and the high removal efficiency of pathogens. In situ thrombolytic or anticoagulant natural materials would be the best choice for hemoperfusion and the nano 2D (two-dimensional) materials with structured channels such as graphene-based materials and COF may show great potential for hemoperfusion, because of their lower possibility of coagulation and their lower penetration resistance implies convenience for modification. The improved hemoditoxifier must show a similar performance as biofilms or biological tissue. Therefore, ligands with high stability in blood that are nontoxic to the human body, and have an excellent specific binding capacity, will become the key to developing hemoperfusion apparatus. For example, electrospun fiber membranes as the matrix structure and aptamers as the affinity ligands may show huge potential for application in the future.

\section{Conflicts of interest}

There are no conflicts to declare.

\section{Acknowledgements}

This work was financially supported by the Fundamental Research Funds for the Central Universities and all the authors would like to thank the National Natural Science Foundation of China (NSFC) (82072201).

\section{References}

1 Q. Zhang, M. Raoof, Y. Chen, Y. Sumi, T. Sursal, W. Junger, K. Brohi, K. Itagaki and C. J. Hauser, Nature, 2010, 464, 104-115.

2 D. H. Morton, K. A. Strauss, D. L. Robinson, E. G. Puffenberger and R. I. Kelley, Pediatrics, 2002, 109, 999-1008.
3 A. S. Morozov, I. V. Bessonov, A. V. Nuzhdina and V. M. Pisarev, Obs. Reanimatol., 2016, 12, 82-107.

4 G. Ankawi, W. Fan, D. P. Montin, A. Lorenzin, M. Neri, C. Caprara, M. de Cal and C. Ronco, Blood Purif., 2019, 47, 94-100.

5 H. Nakae, Acute Blood Purif., 2010, 166, 93-99.

6 T. Rimmelé and J. A. Kellum, Crit. Care, 2011, 15, 205.

7 Y. Zhang, C. L. Mei, S. Rong, Y.-Y. Liu, G.-Q. Xiao, Y.-H. Shao and Y.-Z. Kong, Blood Purif., 2015, 40, 127-132.

8 H. Yatzidis, Proc. Eur. Dial. Transplant Assoc., 1964, 1, 83-87.

9 G. Dunea and W. J. Kolff, Trans. - Am. Soc. Artif. Intern. Organs, 1965, 11, 178-182.

10 K. E. Hagstam, L. E. Larsson and H. Thysell, Acta Med. Scand., 1966, 180, 593-604.

11 M. H. De Myttenaere, J. F. Maher and G. E. Schreiner, ASAIO J., 1967, 13, 190-198.

12 J. G. O'Grady, A. Gimson, C. O'brien, A. Pucknell, R. Hughes and R. Williams, Gastroenterology, 1988, 94, 1186-1192.

13 A. Radomski, P. Jurasz, D. Alonso-Escolano, M. Drews, M. Morandi, T. Malinski and M. W. Radomski, Br. J. Pharmacol., 2005, 146, 882-893.

14 T. M. S. Chang, Kidney Int., 1975, 7, 387-392.

15 M. Odaka, H. Hiraswa, H. Kobayashi, M. Ohkawa, K. Soeda, Y. Tabita, M. Soma and H. Sato, Artif. Organs, 1979, 3, 397.

16 J. Miao, F. Zhang, M. Takieddin, S. Mousa and R. J. Linhardt, Langmuir, 2012, 28, 4396-4403.

17 J. Przepiorski, B. Tryba and A. W. Morawski, Appl. Surf. Sci., 2002, 196, 296-300.

18 J. Koresh and A. Soffer, J. Chem. Soc., Faraday Trans., 1980, 76, 2457-2471.

19 Z. Li, X. Huang, K. Wu, Y. Jiao and C. Zhou, Mater. Sci. Eng., C, 2020, 106, 110282.

20 Y. Yang, S. Yin, C. He, X. Wu, J. Yin, J. Zhang, L. Ma, W. Zhao, C. Cheng and C. Zhao, J. Mater. Chem. B, 2020, 8, 1960-1970.

21 W. Zhao, J. Gu, L. Zhang, H. Chen and J. Shi, J. Am. Chem. Soc., 2005, 127, 8916-8917.

22 Y. Zhu, Angew. Chem., Int. Ed., 2010, 117, 5213-5217.

23 L. Zhang, M. Zhu, L. Guo, L. Li and J. Shi, Nano-Micro Lett., 2009, 1, 14-18.

24 T. Tang, X. A. Li, Y. Xu, D. Wu, Y. H. Sun, J. Xu and F. Deng, Colloids Surf., B, 2011, 84, 571-578.

25 S. Murugavel, J. Toxicol., Clin. Toxicol., 1992, 30, 69-82.

26 C. F. Song, A. F. Zhang, W. Shi, H. R. Jiang and D. T. Ge, IEEE Trans. Nanotechnol., 2011, 10, 626-631.

27 E. Topoglidis, C. J. Campbell, A. E. Cass and J. R. Durrant, Langmuir, 2001, 17, 7899-7906.

28 Z. Yang, S. Si and Y. Fung, Thin Solid Films, 2007, 515, 3344-3351.

29 J. H. Kang, M. Super, C. W. Yung, R. M. Cooper, K. Domansky, A. R. Graveline, T. Mammoto, J. B. Berthet, H. Tobin, M. J. Cartwright, A. L. Watters, M. Rottman, A. Waterhouse, A. Mammoto, N. Gamini, M. J. Rodas, A. Kole, A. Jiang, T. M. Valentin, A. Diaz, K. Takahashi and D. E. Ingber, Nat. Med., 2014, 20, 1211-1216. 
30 J. L. Rosenbaum, M. S. Kramer and R. Raja, Arch. Intern. Med., 1976, 136, 263-266.

31 H. Fang, H. Wei and Y. T. Yu, Biomaterials, 2004, 25, 5433-5440.

32 E. Denti, M. P. Luboz and V. Tessore, J. Biomed. Mater. Res., 1975, 9, 143-150.

33 Y. Yang, S. Q. Yin, C. He, X. Z. Wu, J. R. Yin, J. E. Zhang, L. Ma, W. F. Zhao, C. Cheng and C. S. Zhao, J. Mater. Chem. B, 2020, 8, 1960-1970.

34 Y. P. Li, J. M. Li, Z. Q. Shi, Y. L. Wang, X. Song, L. Y. Wang, M. Han, H. Y. Du, C. He, W. F. Zhao, B. H. Su and C. S. Zhao, Carbohydr. Polym., 2020, 243, 10.

35 H. Wei, L. Han, Y. Tang, J. Ren, Z. Zhao and L. Jia, J. Mater. Chem. B, 2015, 3, 1646-1654.

36 J. Li, Y. Hou, X. Chen, X. Ding, Y. Liu, X. Shen and K. Cai, J. Mater. Sci.: Mater. Med., 2014, 25, 1055-1064.

37 X. Song, X. H. Huang, Z. X. Li, Z. T. Li, K. K. Wu, Y. P. Jiao and C. R. Zhou, Carbohydr. Polym., 2019, 207, 704-712.

38 S. Wu, B. Duan, X. Zeng, A. Lu, X. Xu, Y. Wang, Q. Ye and L. Zhang, J. Mater. Chem. B, 2017, 5, 2952-2963.

39 Y. Li, M. Han, Y. Wang, Q. Liu, W. Zhao, B. Su and C. Zhao, Carbohydr. Polym., 2018, 202, 116-124.

40 Y. Yu, Chin. Sci. Bull., 2013, 58, 4357-4361.

41 K. McCrea, R. Ward and S. P. LaRosa, PLoS One, 2014, 9, 114242-114247.

42 H. Shoji, Ther. Apheresis Dial., 2003, 7, 108-114.

43 R. Zhao, Y. M. Li, X. Li, Y. Z. Li, B. L. Sun, S. Chao and C. Wang, J. Colloid Interface Sci., 2018, 514, 675-685.

44 M. Zhang, L. Zhang, L. H. Cheng, K. Xu, Q. P. Xu, H. L. Chen, J. Y. Lai and K. L. Tung, J. Membr. Sci., 2012, 405-406, 104-112.

45 T. Huang, M. Zhang, L. Cheng, L. Zhang, M. Huang, Q. Xu and H. Chen, RSC Adv., 2013, 3, 25982.

46 K. Wu, X. Song, S. Cui, Z. Li, Y. Jiao and C. Zhou, Appl. Surf. Sci., 2018, 451, 45-55.

47 V. Wernert, O. Schaf, V. Faure, P. Brunet, L. Dou, Y. Berland, P. Boulet, B. Kuchta and R. Denoyel, J. Biotechnol., 2006, 123, 164-173.

48 S. Senel, F. Denizli, H. Yavuz and A. Denizli, Sep. Sci. Technol., 2002, 37, 1989-2006.

49 Y. Ma, J. Chen, J. Li, W. Han, Y. Chai, T. Wang, Q. Zhang, L. Wang, W. Wang, Z. Wang and L. Ou, J. Biomater. Sci., Polym. Ed., 2019, 30, 337-354.

50 S. Kobashi, T. Maruhashi, T. Nakamura, E. Hatabayashi and A. Kon, Acute Med. Surg., 2019, 6, 60-67.

51 J. Zheng, L. Wang, X. Zeng, X. Zheng, Y. Zhang, S. Liu, X. Shi, Y. Wang, X. Huang and L. Ren, ACS Appl. Mater. Interfaces, 2016, 8, 18684-18692.

52 A. Radomski, P. Jurasz, D. Alonso-Escolano, M. Drews, M. Morandi, T. Malinski and M. W. Radomski, Br. J. Pharmacol., 2005, 146, 882-893.

53 C. A. Howell, S. R. Sandeman, Y. Zheng, S. V. Mikhalovsky, V. G. Nikolaev, L. A. Sakhno and E. A. Snezhkova, Carbon, 2016, 97, 134-146.

54 P. Dungkokkruad, S. Tomita, Y. Hiromori, K. Ishida, D. Matsumaru, K. Mekada, H. Nagase, K. Tanaka and T. Nakanishi, J. Toxicol. Sci., 2021, 46, 379-389.
55 T. M. S. Chang, Science, 1964, 146, 524-525.

56 J. Andrade, K. Kunitomo, V. R. Wagenen, B. Kastigir, D. Gough and W. Kolff, ASAIO J., 1971, 17, 222-228.

57 B. Widdop, R. K. Medd, R. A. Braithwaite, A. J. Rees and R. Goulding, Arch. Toxicol., 1975, 34, 27-36.

58 J. A. Vale, A. J. Rees, B. Widdop and R. Goulding, Br. Med. J., 1975, 1, 5-9.

59 T. M. S. Chang, Can. J. Physiol. Pharmacol., 1969, 47, 1043-1045. 60 T. M. S. Chang, Kidney Int., 1976, 10, S218.

61 T. M. S. Chang, A. Gonda, J. H. Dirks, J. F. Coffey and T. Lee-Burns, Trans. - Am. Soc. Artif. Intern. Organs, 1972, 18(465-472), 484.

62 G. S. Kaliaraj, M. Bavanilathamuthiah, K. Kirubaharan, D. Ramachandran, T. Dharini, K. Viswanathan and V. Vishwakarma, Surf. Coat. Technol., 2016, 307, 227-235.

63 Q. Zhang, J. Dong, M. Peng, Z. Yang, Y. Wan, F. Yao, J. Zhou, C. Ouyang, X. Deng and H. Luo, Mater. Sci. Eng., C, 2020, 111, 110847-110854.

64 S. Zheng, Q. Yang and B. Mi, Appl. Surf. Sci., 2016, 363, 619-626.

65 X. Wu, Y. He, G. Lai, R. Zeng and M. Tu, Cellulose, 2020, 27, 10061-10075.

66 H. Chen, X. Wang, Q. Zhou, P. Xu, Y. Liu, M. Wan, M. Zhou and C. Mao, Langmuir, 2017, 33, 13430-13437.

67 L. Wang, G. Li, Y. Lin, Z. Zhang, Z. Chen and S. Wu, Polym. Chem., 2016, 7, 4964-4974.

68 C. R. Emmenegger, E. Brynda, T. Riedel, Z. Sedlakova, M. Houska and A. B. Alles, Langmuir, 2009, 25, 6328-6333.

69 Y.-F. Yang, Y. Li, Q.-L. Li, L.-S. Wan and Z.-K. Xu, J. Membr. Sci., 2010, 362, 255-264.

70 P.-S. Liu, Q. Chen, S.-S. Wu, J. Shen and S.-C. Lin, J. Membr. Sci., 2010, 350, 387-394.

71 Y. Chang, W.-J. Chang, Y.-J. Shih, T.-C. Wei and G.-H. Hsiue, ACS Appl. Mater. Interfaces, 2011, 3, 1228-1237.

72 N. Cai, Q. Li, J. Zhang, T. Xu, W. Zhao, J. Yang and L. Zhang, J. Colloid Interface Sci., 2017, 503, 168-177.

73 L. Zhang, G. Hu, Y. Du, L. Gao and H. Qi, J. Mater. Sci.: Mater. Med., 2018, 29, 113-122.

74 R. Raman, M. A. Raper, E. Hahn and K. F. Schilke, Biointerphases, 2017, 12, 05G603.

75 A. P. Goodwin, S. M. Tabakman, K. Welsher, S. P. Sherlock, G. Prencipe and H. Dai, J. Am. Chem. Soc., 2009, 131, 289-296.

76 H. Lee, J. Rho and P. B. Messersmith, Adv. Mater., 2009, 21, 431-434.

77 R.-L. Liu, Y. Wang, X.-L. Ge, P. Yu, H.-Q. Liu, M.-C. Wang, W. Lu and Q. Fu, J. Biomater. Sci., Polym. Ed., 2017, 28, 1444-1468.

78 N. Hattori and S. Oda, Ren. Replace. Ther., 2016, $2,41$.

79 R. Thomas, A. Abdulnasser, C. Mathilde, D. Olivier, L. Corine, B. Emmanuel, G. Joëlle, É. Jérôme, C. Dominique and B. Giampiero, Nephrol., Dial., Transplant., 2009, 421-427.

80 Y. Okuno, Y. Yamazaki, H. Fukutomi, S. Kuno, M. Yasutake, M. Sugiura, C. J. Kim, S. Kimura and H. Uji, ACS Omega, 2020, 5, 772-780.

81 Y. Qiao, J. Zhao, P. Li, J. Wang, J. Feng, W. Wang, H. Sun, Y. Ma and Z. Yuan, Langmuir, 2010, 26, 7181-7187. 
82 G. C. Ingavle, L. W. J. Baillie, Y. Zheng, E. K. Lis, I. N. Savina, C. A. Howell, S. V. Mikhalovsky and S. R. Sandeman, Biomaterials, 2015, 50, 140-153.

83 A. P. Zavascki, L. Z. Goldani, J. Li and R. L. Nation, J. Antimicrob. Chemother., 2007, 60, 1206-1215.

84 H. Shoji, T. Tani, K. Hanasawa and M. Kodama, Ther. Apheresis Dial., 1998, 2, 3-12.

85 R. P. Dellinger, S. M. Bagshaw, M. Antonelli, D. M. Foster, D. J. Klein, J. C. Marshall, P. M. Palevsky, L. S. Weisberg, C. A. Schorr and S. Trzeciak, JAMA, J. Am. Med. Assoc., 2018, 320, 1455-1463.

86 B. Dahlbäck, Lancet, 2000, 355, 1627-1632.

87 Q. Dang, C. G. Li, X. X. Jin, Y. J. Zhao and X. Wang, Carbohydr. Polym., 2019, 205, 89-97.

88 J. Fevery, Liver Int., 2008, 28, 592-605.

89 Y. Yang, Y. T. Yu, J. C. Song, S. C. Qian, W. L. Quan, X. H. Shao, R. H. Cui and J. Z. Wang, Artif. Organs, 1988, 12, 444-446.

90 H. Zheng, Y. G. Lang, J. Yu, Z. W. Han, B. Chen and Y. F. Wang, Colloids Surf., B, 2019, 178, 80-86.

91 T. G. Drummond, M. G. Hill and J. K. Barton, Nat. Biotechnol., 2003, 21, 1192-1199.

92 W. Su, M. Lin, H. Lee, M. Cho, W.-S. Choe and Y. Lee, Biosens. Bioelectron., 2012, 32, 32-36.

93 S. F. Teng, K. Sproule, A. Husain and C. R. Lowe, J. Chromatogr. B: Biomed. Sci. Appl., 2000, 740, 1-15.

94 X. Jiang, D. Zhou, X. Huang, W. Zhao and C. Zhao, Compos. Sci. Technol., 2017, 504, 214-222.

95 G. Q. Fu, H. Y. Li, H. F. Yu, L. Liu, Z. Yuan and B. L. He, React. Funct. Polym., 2006, 66, 239-246.

96 N. E. Labrou, J. Chromatogr. B: Anal. Technol. Biomed. Life Sci., 2003, 790, 67-78.

97 M. Sternkopf, S. Thoroee-Boveleth, T. Beck, K. Oleschko, A. Erlenkoetter, U. Tschulena, S. Steppan, T. Speer, C. Goettsch, V. Jankowski, J. Jankowski, H. Noels and G. European Uremic Toxin Work, Toxins, 2019, 11, 389-405.

98 L. H. S. Roblee, R. M. Baird and J. W. Tierney, AIChE J., 1958, 4, 460-464.

99 R. F. Benenati and C. B. Brosilow, AIChE J., 1962, 8, 359-361.
100 C. Ronco, P. M. Ghezzi, A. Morris, L. Rosales, E. Wang, F. Zhu, G. Metry, S. L. De, S. Rhamati and R. Adhikarla, Int. J. Artif. Organs, 2000, 23, 125-130.

101 W. R. Clark, F. Ferrari, G. LaManna and C. Ronco, Current Perspectives in Kidney Diseases, Karger Publishers, 2017, vol. 190, pp. 43-57.

102 K. Kogelmann, D. Jarczak, M. Scheller and M. Druener, Crit. Care, 2017, 21, 74-83.

103 K. Tsuchida, R. Yoshimura, T. Nakatani and Y. Takemoto, Ther. Apheresis Dial., 2006, 10, 25-31.

104 C. Ronco, A. Brendolan, G. Lonnemann, R. Bellomo, P. Piccinni, A. Digito, M. Dan, M. Irone, G. La Greca, P. Inguaggiato, U. Maggiore, C. De Nitti, M. L. Wratten, Z. Ricci and C. Tetta, Crit. Care Med., 2002, 30, 1250-1255.

105 S. Brandt, R. A. Goffe, S. B. Kessler, J. L. Oconnor and S. E. Zale, Bio/Technology, 1988, 6, 779-782.

106 E. Klein, J. Membr. Sci., 2000, 179, 1-27.

107 P. M. Honore, R. Jacobs, O. Joannes-Boyau, J. De Regt, E. De Waele, V. van Gorp, W. Boer, L. Verfaillie and H. D. Spapen, ASAIO J., 2013, 59, 99-106.

108 W. R. Clark, D. Gao, A. Lorenzin and C. Ronco, Contrib. Nephrol., 2018, 194, 70-79.

109 Y. Li, M. Biisembaev, Q. Gong, S. Aknazarov, F. Lu, Y. Huang, X. Zhao, K. Du, J. Bai, J. Gan, M. Zhao and D. Zhuang, ACS Omega, 2019, 4, 18930-18935.

110 Z.-M. Huang, Y.-Z. Zhang, M. Kotaki and S. Ramakrishna, Compos. Sci. Technol., 2003, 63, 2223-2253.

111 L. Feng, S. Li, H. Li, J. Zhai, Y. Song, L. Jiang and D. Zhu, Angew. Chem., Int. Ed., 2002, 41, 1221-1223.

112 G. M. Whitesides and B. Grzybowski, Science, 2002, 295, 2418-2421.

113 Z.-M. Huang, Y.-Z. Zhang, M. Kotaki and S. Ramakrishna, Compos. Sci. Technol., 2003, 63, 2223-2253.

114 C. Ronco and D. J. Klein, Crit. Care, 2014, 18, 309-315.

115 H. L. Simons, US Pat., US19630251693, 1966.

116 X. Lu, C. Wang and Y. Wei, Small, 2009, 5, 2349-2370.

117 Y. Huang, Z. Yuan, D. Zhao, F. Wang, K. Zhang, Y. Li, Y. Wen and C. Wang, Eur. Polym. J., 2019, 110, 69-75.

118 J. Wang, L. a. Hou, Z. Yao, Y. Jiang, B. Xi, S. Ni and L. Zhang, Chem. Eng. J., 2021, 406, 126822-126831. 